\title{
Fascinating Communication in Honey Bees
}

\author{
Pratiksha Sanjay Bandgar ${ }^{1 *}$, Kajal Appasaheb Pondkule ${ }^{2}$ and Vitthalrao B. Khyade ${ }^{3}$ \\ ${ }^{1}$ Shardabai Pawar Mahila Mahavidyalaya, Shardanagar Tal. Baramati Dist. \\ Pune - 413115, India \\ ${ }^{2}$ Malegaon Sheti Farm, Agricultural Development Trust Baramati, Shardanagar, (Malegaon \\ Khurd) Post Box No - 35, Baramati, Pune 413 115, Maharashtra, India \\ ${ }^{3}$ Department of Zoology, Shardabai Pawar Mahila Mahavidyalaya, Shardanagar Tal. \\ Baramati Dist. Pune - 413115, India \\ *Corresponding author
}

\section{Keywords}

Bee dance language,

Competition, Foraging,

Communication, Signals

of danger

Article Info

Accepted:

26 August 2018

Available Online:

10 September 2018

\section{A B S T R A C T}

Forager bees communicate their floral findings in order to recruit other worker bees of the hive to forage in the same area. The factors that determine recruiting success are including evaluations of the quality of nectar and/or pollen brought in. The waggle dance and odor plume are the two hypotheses for explaining "foragers recruit other workers bees in hive". The dance theory is far more widely accepted, and has far more empirical support than the odor theory. Supporters of the dance theory often grant odor a significant role in recruitment, while supporters of the odor theory have claimed that the dance is essentially irrelevant to recruitment. The academic debate between these theories has been polarized and sometimes hostile. Asian honey bees provide fascinating in sights into the evolution of honey bee foraging communication. Although all honey bees use the waggle dance to communicate resource location, variations in the waggle dance and in the biology of Asian species have led to several different hypotheses about how and why this famous behavior evolved. In this review, my goal is to suggest areas of research and questions that will help us understand the evolution of honey bee foraging communication in greater detail. Specifically, I would like to draw attention to the selective pressures imposed by direct competition and aggression over floral resources and nest robbing, signals related to danger, and experiments that may allow us to resolve questions about honey bee dance dialects. I hope that these suggestions will stimulate more research in Asian honey bees and allow us to develop a better overall picture of the evolution of foraging communication in the corbiculate bees (Hymenoptera, Apidae).

\section{Introduction}

Honey bees are an important model for the study of animal communication because they use functionally referential communication to encode the distance and direction to a food source (von Frisch, 1967). As Karl von Frisch aptly stated, this system has been a "magic well" for Behavioral Ecologists and Neuroethologists, continually providing important new insights (Giurfa, 2007). Biologists know the most about one species, 
Apis mellifera, and it is therefore encouraging to see growing interest in other species of honey bees (Hepburn and Radloff, 2011). The famous honey bee waggle dance and the variations that exist in different species have been recently well reviewed (Duangphakdee et al., 2011). Therefore, my goal is not to provide a comprehensive survey, but to select a few threads in this fascinating story that would be profitable to investigate. I would like to increase our understanding of why and how honey bee recruitment communication has evolved by stimulating research in specific areas. The exact number of honey bee species is debated, but many taxonomists recognize nine species: the dwarf honey bees ( $A$. andreniformis and $A$. florea), the medium sized bees (A. mellifera, A. cerana, A. koschevnikovi, $A$. nigrocincta, and $A$. nuluensis), and the giant honeybees (A. dorsata and A. laboriosa) (Radloff et al., 2011). I will focus on the Asian honey bees, primarily $A$. florea, A. andreniformis, $A$. dorsata, and $A$. cerana. It should be noted that A. cerana behaviors described in the literature may also apply to $A$. koschevnikovi, $A$. nigrocincta, and $A$. nuluensis given that recognition of these other species is relatively recent (Radloff et al., 2011).

\section{Selective pressures influencing honey bee foraging}

Studies on apiculture have focused on two selective pressures influencing honey bee foraging: (1) the spatial distribution of food sources and (2) competition. Rich, clumped food sources can be valuable to recruit for (mass foraging), whereas more dispersed food sources may be better exploited by individual foragers that do not recruit to a specific location (Dornhaus 2002). In A. mellifera, colonies in temperate habitats (less clustered food) in which waggle dance location information was eliminated, gained the same weight as controls. However, colonies in an
Asian tropical forest with more clumped food resources (determined from undisturbed waggle dances), gained significantly less weight when waggle dance location information was eliminated (Dornhaus and Chittka, 2004). In addition, the role of resource spatial patchiness has been modeled, demonstrating the theoretical advantages of location communication for rich clumped food sources (Dornhaus et al., 2006). How competition has shaped honey bee foraging communication is less well understood. Honey bees are foraging generalists that collect nectar and pollen from a wide variety of species (Michener, 1990). There is evidence for ecological niche overlap among Asian honey bees. For example, A. florea and A. dorsata visit many of the same floral species (Abrol, 2011). Although A. mellifera is an introduced species in Asia, it is now in competition with native species, likely adding to competition that already existed among native species. For example, experimental removal of A. mellifera increased the number of $A$. cerana visiting four crop plants (Partap et al., 2000). Honey bees can reduce such competition by foraging at different times. The flowers of Pterocarpus santalinus open at midnight and are visited extensively by $A$. dorsata on moonlight nights from midnight until dawn. Apis cerana and $A$ florea visit only during early morning hours, competing with each other, but avoiding direct competition with A. dorsata (Rao and Raju, 2002). Honey bees can avoid competition by foraging on different plant species. Apis florea will visit species whose flowers provide low caloric rewards whereas $A$. dorsata prefers flowers with high caloric rewards. Apis florea visited several species such as Daucus carota, Allium cepa, and Trigonella foenumgraecum that were not visited by A. dorsata. However, specialized attraction may not always relate to caloric rewards. Apis florea was more attracted to Brassica campestris blossoms, even though these were less rewarding than Cajanas cajan flowers (Sihag and Rathi, 
1992). In addition, different floral nectar compositions are favored by different species (Abrol, 2011). Species can also avoid competition by foraging under different environmental conditions and at different times of day (Abrol, 2011).

\section{Conflict and aggression in honey bees}

The correlation between Juvenile Hormone and levels of aggressiveness within a colony suggests a regulatory role for Juvenile Hormone, but variation among colonies involves factors other than Juvenile Hormone. When multiple species simultaneously forage on the same resource, conflicts can occur. For example, A. florea exhibited aggression towards A. mellifera on flowers (Chahal et al., 1986). More studies that examine aggression and conflict among native Asian species at natural food sources would be highly useful. However, research using artificial feeders and a mixture of native and introduced species (mainly A. mellifera) is still revealing. When A. mellifera and $A$. cerana were trained to separate sucrose feeders $(50 \%$ sucrose w/w) that were gradually brought closer together, aggression arose. Ultimately, A. mellifera were dominant and completely excluded $A$. cerana (Dhaliwal and Atwal, 1970). At sugar water feeders, researchers found an aggression hierarchy among different Asian species. Apis florea was dominant over A. cerana, which was dominant over A. dorsata. Apis florea attacked $A$. cerana 13 fold more times than vice versa and $A$. cerana attacked $A$. dorsata 3 fold more times than vice versa. Conspecific aggression also occurred between A. cerana colonies (Koeniger and Vorwohl, 1979). Similarly, Ruttner (1988) found that Apis dorsata was attacked by $A$. cerana, not by $A$. florae or A. mellifera. At an artificial sucrose feeder, A. florea and A. cerana could dominate the feeder, excluding the larger $A$. dorsata and chasing off other species. In this study, $A$. florea and A. cerana foraged together without exhibiting aggression (Ruttner, 1988). Overall, small-bodied species exhibited more aggression and were dominant relative to larger-bodied species. This hierarchy is counterintuitive because the larger individual usually beats the smaller in animal contests (Alcock, 2001). However, in social insects, the ability of the colony to recruit large numbers of individuals plays a role. One can apply the concept of the contestant size to superorganism (colony) size, not merely the size of an individual forager. A colony that can mass recruit a larger number of smallerbodied workers can win against a fewer number of larger-bodied ones (Lichtenberg et al., 2010). Nonetheless, it is fascinating that in one-on-one contests a smaller bee can win over a larger one (Koeniger and Vorwohl, 1979; Ruttner, 1988). This phenomenon is widely observed in stingless bees (Johnson, 1974; Johnson and Hubbell, 1974; Roubik, 1978; Roubik, 1981; Johnson, 1983; Nagamitsu and Inoue, 1997; Nieh et al., 2005). One explanation is that smaller species are more limited in flight range than larger species (Greenleaf et al., 2007). Therefore, the smaller-bodied species invest more effort and will take greater risks when fighting to defeat a larger-bodied species, which can abandon the contested patch to search for one further away (Koeniger and Vorwohl, 1979). A more complete understanding of social bee competition for floral resources should also include other bees, particularly the stingless bees, which can exhibit high levels of aggression and displace honey bees on natural food sources (Nagamitsu and Inoue, 1997). Apis koschevnikovi and stingless bees visited honey water feeders placed at different heights in towers (Nagamitsu and Inoue, 2005). In a separate experiment, stingless bees attacked $A$. koschevnikovi at honey water feeders, but $A$. koschevnikovi never exhibited aggression against stingless bees (Nagamitsu and Inoue, 1997). Honey bee nests provide rich resources. Inter- and intra-specific nest robbing can 
therefore occur, particularly when a colony is poorly defended. Apis indica and A. mellifera colonies can rob each other, depending on which colony is weak (Atwal and Dhaliwal, 1969). In an apiary containing both $A$. cerana and A. mellifera, A. cerana initiated robbing of A. mellifera colonies more than vice versa, but A. cerana colonies were more likely to die during conflicts with A. mellifera colonies (Yang et al., 2011). Among native Asian species, robbing occurs between A. dorsata and $A$. cerana (Atwal and Dhaliwal, 1969). In some cases, robbing by $A$. dorsata can reduce the survival of $A$. indica colonies (Singh, 1959). As with floral food competition, the extent of nest robbing among sympatric native Apis species is poorly understood. It would be useful to determine the patterns of interspecific nest robbing among different native species of Asian honey bees. Is there a hierarchical pattern, similar to a dominance hierarchy, in how species interact during nest robbing? The mechanisms that allow certain species to win fights against others remain poorly understood. In fights over a feeder, $A$. mellifera stung and killed A. cerana (Dhaliwal and Atwal, 1970). However, during intraspecific fights between $A$. mellifera foragers over an artificial feeder, rarely observed stinging. The primary mode of $A$. mellifera attack, as in stingless bees, involves biting (Nieh et al., 2005; Lichtenberg et al., 2010; Nieh, 2010). Thus, species may adopt different attack strategies depending upon the competition.

At nests, A. florea displaced A. mellifera on comb and fought with $A$. mellifera guards to rob their nest (Chahal et al., 1986). Although A. mellifera guards bit and pulled at the robbers on their legs, wings, and other body parts, A. florae often managed to escape. How they did so is unclear, but understanding their ability to escape may explain how they eventually won and successfully robbed the colony. Apis florae was able to sting and avoid being stung. Out of 124 dead A. mellifera, $14 \%$ had been stung by $A$. florea, but $0 \%$ of $A$. florae had been stung by $A$. mellifera (Chahal et al., 1986). Interestingly, once the colony had "submitted" there was relatively little resistance from the invaded $A$. mellifera (Chahal et al., 1986). This is reminiscent of the behavior of a stingless bee colony that initially fights and then retreats when invaded by the robber stingless bee, Lestimelitta limao (Sakagami et al., 1993). This phenomenon of "submission," how it occurs, and what triggers it would be fascinating to study. From the perspective of the superorganism, how is the consensus to cease fighting achieved?

\section{Signaling honey bees about danger}

The new study by Nieh (Nieh, 2010) reveals that a bee that has had a traumatic or 'unpleasant' experience at a food site - such as an injury, or an attack from another insect or bee - can generate a warning signal to prevent other bees from being recruited to visit that site. She does this by butting her head against a dancing bee that is advertising the site, and emitting a brief buzzing tone (Michelsen, et al., 1986). This 'danger' signal causes the dancer to stop dancing, and hence to stop further recruitment to that site (Nieh, 2010). What constitutes such an 'unpleasant' experience for a bee when it feeds at a flower? An attack by a waiting spider, a mantid, or a predacious bug would be one kind of example. Such predators often keep station at nectarbearing flowers to ambush visiting bees. Another example of an undesirable experience would be a debilitating fight with a bee visiting the flower from another colony. These fights arise because colonies often compete for the same food source, and bees distinguish between their own hive mates and other bees by sensing their body (cuticular) odours: bees from different colonies carry different olfactory signatures. Nieh (Nieh, 2010) finds that gently pinching the leg of a bee (to 
simulate a bite from another insect) while it visits a feeder can induce the bee to direct 'danger' signals toward dancing bees when it returns to the hive (Nieh, 2010). In the case of fights between rival-colony bees, Nieh finds, interestingly, that a bee returning from a fight will signal danger only when she has lost a battle and is wounded, not when she has won and returned uninjured (Nieh, 2010). Another stimulus that evokes the perception of danger in a visiting bee is exposure to the so-called 'alarm pheromone' - a pheromone that bees exude when they perceive threat or are in a behaviourally aggressive state. A puff of this pheromone, delivered to a bee when she visits the feeder, causes her to stop other bees from dancing to advertise the food source when she returns home (Nieh, 2010). In general, the effects of competition and fighting on food recruitment communication are not well understood. This is a part of the evolutionary story that remains to be fully explored. There is evidence for negative feedback signaling that counteracts the positive feedback produced by recruitment dances. During competition for a feeder, A. mellifera foragers that were attacked, returned to the nest and produced "stop signals." The stop signal is a brief vibrational signal lasting around $150 \mathrm{~ms}$ (Kirchner, 1993) at $380 \mathrm{~Hz}$ (Michelsen et al., 1986) and is frequently delivered by a sender butting her head into a recipient, most frequently waggle dancers (Nieh, 1993). The stop signal or "brief piping signal" (Seeley and Tautz, 2001; Thom et al., 2003) was originally described as a food begging call (Esch 1964; von Frisch 1967). However, it does not elicit food exchange (Nieh, 1993; Pastor and Seeley, 2005). Instead, it causes waggle dancers to stop dancing and leave the nest (Kirchner, 1993; Nieh, 1993; Pastor and Seeley, 2005). Bees produce stop signals under natural conditions and signal recipients waggle dancing for natural resources will reduce their waggle dancing (Pastor and Seeley, 2005). Natural and synthesized signals significantly increased waggle dancer departure (Nieh, 1993). Stop signal playbacks reduced waggle dance durations by $59 \%$ and recruitment by $60 \%$ (Kirchner, 1993). In addition, deteriorating foraging conditions (crowding or increased feeder wait time) increase stop signal production (Thom et al., 2003; Lau and Nieh, 2010). During competition for a rich food source, $A$. mellifera competitors attacked resident bees. Bees that were attacked (victims) increased the number of stop signals by 43 fold and sharply decreased (by 12.6 fold) the number of waggle dance circuits performed. Bees that were undi sturbed (received and gave no attacks) and bees that attacked competitors continued to recruit and produced almost no stop signals (Nieh, 2010). In addition, signalers targeted bees that smelled like the odor at their feeding location. The proximate causes of stop signal production can be further broken down into receiving physical aggression (biting) and detecting alarm pheromone (Nieh, 2010). There is a benefit to such a signal. Each individual forager decides on whether and how much to recruit. However, one individual's decision to cease recruiting does not stop recruitment by other waggle dancers. By sending stop signals, she can inform foragers visiting the same location of adverse foraging conditions and give negative feedback to counteract waggle dancing by others. Broadly, collective foraging of the superorganism arises from the positive and negative feedback of multiple agents, with negative feedback cycles evidently providing greater precision and speed for labor reallocation. Whether this occurs in other species of honey bees, particularly Asian species, is unknown. However, given the evidence for interspecific aggression at floral resources and during nest robbing, Asian species of honey bees may also have the stop signal. A comparative analysis could help us to understand how this signal functions and how it may have evolved. The 
stop signal is related to the experience of danger at a food source, and falls within a larger class of movement and vibrational signals related to danger. It would therefore be informative to examine other danger-related signals and see if they share common features. Several defensive behaviors (some of which may be signals) could be better understood. Defensive hissing signals are one example. Butler (1954) described a combined body shaking and hissing in A. cerana. Apis mellifera cypria produces high frequency hissing sounds when being attacked by the hornet, Vespa orientalis (Papachristoforou et al., 2008). Such hissing has not been reported in other subspecies of A. mellifera, although they are also attacked by wasps.

Apis florea workers produce a hissing sound during nest defense, combined with slight wing movements. These behaviors spread to nearby bees and may deter certain predators (Sarma et al., 2002). It would be informative to learn if other Asian honey bee species produce hissing sounds when attacked by predators. The nests of open nesting species are more exposed to predators than nest cavity dwelling species. Open nesting species have thus evolved some interesting deterrents and signals. Apis nuluensis performs defensive shaking behaviors in response to hornet predators. This shaking recruited guards to the predator's location and also induced shaking in nearby bees (Koeniger et al., 1996).

Apis dorsata produces shimmering patterns consisting of adjacent bees flipping their abdomens upwards. This motion spreads throughout the comb surface in a wave-like pattern, and is stimulated by the presence of a predator, such as a wasp (Schmelzer and Kastberger, 2009). Detailed video analyses show that wasps avoided the shimmering surface and were therefore prevented from directly capturing shimmering bees (Kastberger et al., 2008). There may be specialization in which workers perform the shimmering, since it is primarily triggered in the area where foragers arrive, dance, and then depart (Schmelzer and Kastberger, 2009). Finally, drones are generally not thought to play a major role in colony defense. However, A. cerana drones reportedly participated in shimmering. Drone shimmering wing motions were less distinct than those of the workers, but were distinguishable (Sakagami, 1960). Drone defensive behavior would be profitable to study because so little is known about what drones contribute to the colony, aside from their task of mating with virgin queens.

\section{The precision of location communication}

What constrains the precision of the waggle dance? There is a continuous transition between round dancing and waggle dancing: from dances that provide no or small amounts of location information to dances that provide precise distance and direction information (von Frisch, 1946; Gardner et al., 2008). Interestingly, there can be substantial variation in the waggle phase angle (divergence angle), but this generally decreases as the distance to the resource increases (Towne and Gould, 1988). Two explanations have been proposed for this variance. The adaptive hypothesis states that this variance increases colony exploitation of resource patches by scattering recruits. Resources such as nectar or pollen typically occur in patches, not as points (unlike nest sites, Gould, 1975; Weidenmuller and Seeley, 1999). Therefore, the adaptive hypothesis predicts that waggle dances for nest sites should exhibit greater precision (less variance in waggle phase direction) than dances for food sources, at least for close distances. In the adaptive hypothesis, natural selection has shaped the divergence angle to improve colony foraging efficiency and nest migration. The constraint hypothesis states that this variance results from sensory and performance constraints. Under this 
hypothesis, the divergence angle is not a specific adaptation shaped by natural selection in response to food source patchiness and house hunting. Rather, it arises from constraints on sensory mechanisms that bees use to orient their dances. The constraint hypothesis proposes that bees are "doing the best they can" given the conditions they experience while dancing. For example, $A$. mellifera foragers with visual references during dancing had a smaller divergence angle than when they were deprived of visual references (Tanner and Visscher, 2010). Since they normally have visual references while dancing, the open-nesting Asian honeybees provide an interesting natural test of the importance of visual constraints in the dance language. For example, in A. florea, there was a lull between noon and 1:00 pm in absconding dances, perhaps because of increased difficulty in determining the sun's azimuth when it was at its highest point in the sky (Atwal and Dhaliwal, 1969). In Iran, $A$. florea built combs in which the horizontal section was clearly exposed to blue sky, perhaps to facilitate orientation (Tigari, 1971). Early experiments on open-nesting Asian species (A. florea, A. cerana, and A. dorsata) showed significantly smaller divergence angles than for A. mellifera at comparable distances (see Fig. 12 of Towne and Gould, 1988). However, Beekman et al., (2008) studied the spatial precision of A. florea waggle dances and found no significant differences between dance divergence angles for nest sites (point sources) and food sources (patches). Beekman et al., (2008) also found no significant difference between waggle phase durations (which provide distance information) for nest sites or food sources.

Weidenmuller and Seeley (1999) studied $A$. mellifera, and likewise found no differences in waggle phase durations for nest sites or food sources. However, Beekman et al., (2008) found an effect of distance on variance in waggle phase duration. In A. florea, variation in this distance information increased as the distance to the food source increased. Thus, as the distance to the resource increased, the distance information became less precise. This is different from what is reported for $A$. mellifera, where distance and direction information became more precise with increasing distance (Towne and Gould, 1988). Beekman et al., (2008) thus suggested that directional information may be more important than distance information in $A$. florea. This matches what is reported for $A$. dorsata workers dancing on the surface of a swarm for nest sites (Dyer and Seeley, 1994). These dancers exhibited consistent directionality but highly variable waggle phase durations (mean waggle phase duration of 42 dancers was $20.8 \pm 16.5 \mathrm{~s}$, with a range of 6.4 to $72 \mathrm{~s}$ ). In contrast, dances for food sources exhibited less variance in dance circuit duration. Given the evident low level of waggle dance distance information in A. florea (for food sources) and A. dorsata (for nest sites), it would be useful to examine the precision of distance communication in these species using feeder or nest site arrays. Interestingly, the same increase in imprecision with increasing distances (putatively conveyed through the duration of recruitment sound pulses) is reported in the stingless bees, Melipona panamica, M. mandacaia, and $M$. bicolor (Nieh and Roubik, 1998; Nieh et al., 2003). Is there something about the habitat of tropical species that makes precise distance communication less important? In terms of the constraint hypothesis, studies on the effect of dancing on a vertical comb vs. a horizontal comb would be informative, as Beekman et al., (2008) suggest. Such dances occur naturally in A. florea, which has a relatively flat portion of the comb above the plant branch holding the nest. For this species, horizontal dancers should rely only upon vision for orientation whereas vertical dancers could use vision and gravity. 


\section{Distance Coding in Honey Bee}

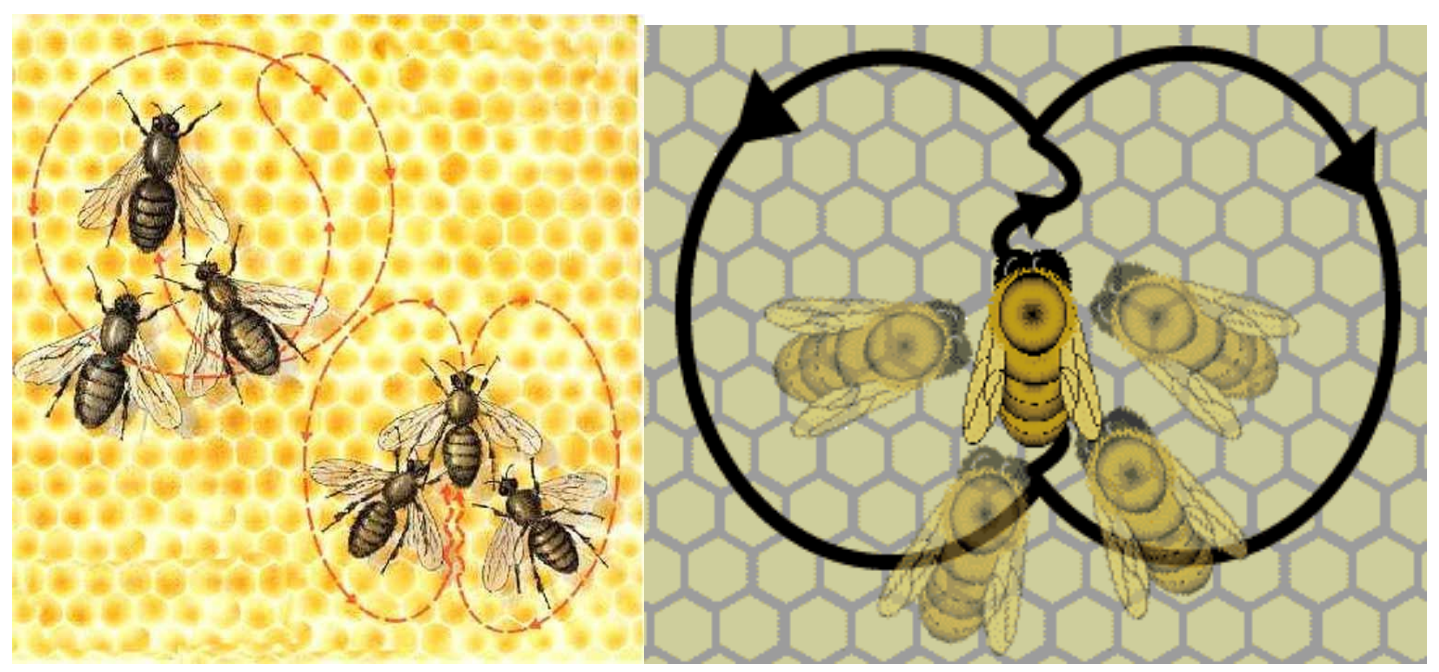

Careful experiments with this species may reveal if there are sensory constraints on waggle dance precision. One predicts that, in A. florea, for any given location, waggle dancers using multimodal orientation information (vision and gravity: on vertical comb surface) should exhibit different divergence angles from dancers using single modal visual information (on the horizontal comb surface).

\section{Distance coding in honey bee}

If one plots the duration of the waggle phase performed for any given distance, the duration of the waggle phase increases with increasing distance to the food source (von Frisch, 1967). The resulting curve is called the "dialect curve" or the "distance coding curve." Has this dialect curve been shaped by the typical foraging range of a species? Some researchers have reported different codings of distance between honey bee species (Lindauer, 1956; Punchihewa, Koeniger et al., 1985). These "dialects" may be shaped by species foraging ranges, based upon two assumptions. The first assumption is that steep dialect curves are more precise (providing a greater difference in signaling per unit increase in distance signaled). The second assumption is that the total steepness is constrained such that shorter maximum forager distances should correspond to steeper curves. Thus, species with different foraging ranges should have different distance codings. Early research reported that smaller bodied species (with smaller forager ranges) had steeper dance dialect curves (Lindauer, 1956; Boch, 1957; Gould, 1982; Punchihewa, Koeniger et al., 1985; Towne and Gould, 1988). More recently, Su et al., (2008) compared the distance curves for A. cerana and $A$. mellifera and found significant slope differences. They reported that the distance curve slope for A. cerana was significantly steeper than for A. mellifera. However, Dyer and Seeley (1991) found no significant differences between the distance coding "dialects" of the different Asian species of honeybees (A. florea, A. cerana, and A. dorsata) although, based upon decoding dances for natural food sources, there were significant differences in flight ranges. The larger-bodied species, A. dorsata, had the largest foraging range $(95 \%$ of dances were for distances estimated to be less than $3.8 \mathrm{~km}$ ) compared to the smaller-bodied A. florea (1.3 $\mathrm{km}$ for the $95 \%$ point) or smaller-bodied $A$. cerana $(0.9 \mathrm{~km}$ for the $95 \%$ point $)$. The observations over a variety of seasons are 
required for a more robust test of the dance dialect tuning hypothesis (Dyer and Seeley, 1991). They conclude that their data may support the hypothesis of different dance dialects, but do not support the idea that dialects are strongly shaped by the maximum foraging distance of each respective species. They suggest that visual sensory constraints may explain why open nesting bees ( $A$. dorsata and $A$. florea) have relatively long maximum dance circuit durations in comparison with A. mellifera and A. cerana, which nest in cavities. Instead of examining the slope of the dialect curve, one can measure the transition distance from round to waggle dancing. Towne and Gould (1988) found differences such that A. florea, $A$. dorsata, and $A$. cerana transitioned to waggle dancing (called "oriented dances" in their paper) at much shorter distances $(<10 \mathrm{~m})$ than A. mellifera (>50 m). Whether these Asian species actually use this waggle dance information at such close distances and how precise recruits are would be useful to determine. However, Sarma et al., (2004) found no differences between the distances at which A. mellifera carnica and A. florea transitioned from round to waggle dances. Their paper introduces a useful technique of counting the number of circling runs and waggle phases. This avoids the problem of classifying the dance as either a round or a waggle dance, which can be difficult in borderline cases, and is a method that future studies may wish to use. These differing results could arise if there is considerable intraspecific variation in the distance coding curves of each species. No studies, to my knowledge, have explicitly examined this by testing several colonies of the same species with the same procedures, but in different locations. Some intraspecific variation is expected. The distance at which a forager transitions from round to waggle dancing appears to be controlled by a single locus with multiple alleles (determined in a genetic backcross with different strains of A. mellifera (Rinderer and Beaman, 1995; Johnson, Oldroyd et al., 2002; Oldroyd and Wongsiri, 2006). Recently, genomic changes have been detected when individuals were forced to shift from foraging at perceived short distances to perceived long distances by manipulating optic flow (Sarma, Rodriguez-Zas et al., 2010). Another explanation for the dialect differences measured by some authors and the lack of strong dialect differences measured by Dyer and Seeley (1991), lies in the optic flow bees experienced in these different experiments. Apis mellifera measures distance by measuring optic flow (Srinivasan, Zhang et al., 1997; Srinivasan, Zhang et al., 2000; Esch, Zhang et al., 2001). This likely is the same for all Apis species, because at least one species of stingless bee (Melipona seminigra) uses optic flow to measure distance (Hrncir et al., 2003), and one species of bumble bee (Bombus impatiens) can use optic flow during flight orientation (Dyhr and Higgins, 2010). Given what we now know about the importance of optic flow in A. mellifera distance estimation, it would be useful to test Asian species for distance dialect differences using optic flow tunnels that allow for more controlled comparisons. Comparisons in natural habitats need to control for differences in optic flow that are perceived along the foraging route. For example, honey bees trained to fly through an optically dense habitat performed longer waggle phases than those trained to the same linear distance in a less optically dense habitat (Tautz, 2008). In general, it would be useful to check whether the Asian honey bees (1) also use optic flow to measure distance and (2) how their odometer is calibrated and compares with what is known for A. mellifera. As an aside, more research on the vision of Asian honey bees would beneficial, not only to better understand visual resolution and parameters that influence the perception of optic flow, but also to understand the fascinating 
phenomenon of night foraging. Apis dorsata eyes have large ocelli and are more sensitive to dim light than those of other Apis species (Somanathan et al., 2009). The bright yellow flowers of Pterocarpus santalinus open at midnight and are visited extensively by $A$. dorsata on moonlit nights (Rao and Raju, 2002). However, the waggle dances of $A$. dorsata are evidently oriented towards the unseen sun, not the moon (Dyer, 1985a). This raises the question of how these bees are able to avoid orienting towards a bright object in the sky (the moon) as a replacement for the sun, when A. mellifera generally accepts a bright object such as a lamp and uses this as a substitute "sun" (Gould, 1975). Controlled experiments with $A$. dorsata colonies on moonless nights or in a darkened area and a light source of variable brightness could help to determine what levels of brightness this species finds acceptable as a substitute sun. It would be interesting to compare this threshold level of brightness with other species that do not forage at night. Finally, do dance dialect differences actually matter? How is recruitment precision affected? Tan et al., (2009) created mixed colonies of A. mellifera and $A$. cerana and examined what happened when sender and receiver were the same or different species. They trained bees to feeder placed $130 \mathrm{~m}$ away within a linear array of four feeders. There were differences in the number of bees recruited by intra- or interspecific recruits. Surprisingly, precision of communication (where recruits showed up) was not significantly different between sameor mixed-species pairs (Tan et al., 2009) or in a similar experiment where foragers from mixed-species colonies were trained to a more distant, $500 \mathrm{~m}$ feeder array (Su et al., 2008).

Honey bees (Apis mellifera), is one of the social insects that live in well-organized society. Each member of this complex society has a job to do in order to maintain hive's organization. Communication techniques maintain organization in these complex societies. Much remains to be learned about why and how the honey bee waggle dance evolved and how, as a powerful force for positive feedback, it is countered by negative feedback communication. In testing the importance of various selective factors, it is important to recognize that the value of recruitment and recruitment information varies with multiple factors such as colony need, the availability and patchiness of food sources in the environment, and the experiences of foragers. Given this range of factors, it is perhaps not surprising that experiments are sensitive to small changes in methodology and to the motivation of and private information possessed by recruits. One example of this complexity is shown in the different classifications of foragers: scouts, reactivated foragers, and experienced foragers. These categories reflect the motivation of individual bees to seek out certain types of information and food sources, and these like arise from a motivational continuum. This should increase variance in the different behavioral outcomes. Recruiter motivation may also affect waggle dancing in more subtle ways, not just changing the number of dance circuits, but also varying how the dance is performed. Honey bees may not perform many waggle dances and can be very difficult to train to an artificial feeder (even a rich one) when there is abundant natural food. Whether the motivation to recruit also affects the accuracy of waggle dance information remains unclear, but it is known that waggle dances, at least in $A$. mellifera, can exhibit a wide range of variation and "excitement" from the classic "figure eight" to a forager that produces sporadic waggle phases interspersed by meandering around the nest. Studies that examine this variation in detail would be illuminating, particularly by obtaining comparative data from the Asian honey bees. In closing, I would like to note that several 
phylogenetic trees have been suggested for Apis. These different trees influence our hypotheses on how the waggle dance evolved. It is tempting to see in the waggle dance the ritualized path of a forager as she leaves the colony to collect food (waggle phase), returns to the nest to unload her collected food (return phase), and then returns to collect more food (waggle phase) again. The beautiful pattern of the waggle dance thus traces, in miniature, her foraging cycle. This analogy could be extended to the round dance, which occurs when the resource is close to the nest. Round dances can have a minor directional component, but largely consist of circular "return phases." One can call this scenario 1. In this scenario, the ancestral waggle dance pointed directly at the food source and was performed on a horizontal surface. Later, the complication of cavity-nesting (which provides no to very limited horizontal surfaces and limits visual orientation) led bees to dance on vertical surfaces, and thus the gravity oriented vertical waggle dance evolved. The real story may not be so elegant. The ability to dance on horizontal surfaces could be derived (scenario 2). In scenario 2, based upon molecular analyses and the cavity-nesting habits of all Euglossini, all Bombini, and most Meliponini, the Apis ancestor was a cavity nesting species. All cavity nesting species build vertical honeycombs. All honey bees species waggle dance, and thus the ancestral Apis likely performed the waggle dance on a vertical comb. The small honey bees, A. florea and A. andreniformis, would then have evolved to nest on branches, where they have a horizontal component to their comb (the part above the branch) and a clear view of visual markers such as celestial cues to orient an evolutionary innovation, horizontal dances. Interestingly, A. florea seems unable to use gravity orientation for waggle dancing and lacks some of the gravity receptors found in other Apis species. When A. florae foragers are forced to dance on a vertical surface, such as formed by a swarm, or in experiments in which the comb is rotated, they will dance such that their waggle run points at the goal, not with reference to gravity. Instead, visual stimuli play an important role. Alternatively, if we adopt scenario 1, Apis first evolved horizontal dances that pointed directly at the food source and then evolved vertical dances, but never lost the ability to perform horizontal dances. Thus, the existing species of Apis may not provide definite information about how the waggle dance evolved. However, detailed studies of what these species are capable of will still be valuable for understanding the communication of these fascinating organisms.

\section{Acknowledgement}

Academic support received from International Science Community Association (ISCA); Agriculture Development Trust, Baramati and the International Journal of Current Microbiology and Applied Sciences (IJCMAS) deserve appreciation \& exert salutary influence.

\section{References}

Abrol DP. 2011. Foraging. pp 257-292. In: Hepburn HR, Radloff SE (eds). Honeybees of Asia. Springer-Verlag, Berlin.

Alcock J. 2001. Animal behaviour: an evolutionary approach. Sunderland, Massachusetts: Sinauer Associates.

Atwal AS, Dhaliwal GS. 1969. Robbing between Apis indica $\mathrm{F}$ and Apis mellifera L. Am Bee J 109: 462-463.

Beekman M, Gloag RS, Even N, Wattanachaiyingchareon W, Oldroyd BP. 2008. Dance precision of Apis floreaclues to the evolution of the honeybee dance language? Behav Ecol Sociobiol 62: $1259-1265$. 
Biesmeijer JC, de Vries H. 2001. Exploration and exploitation of food sources by social insect colonies: a revision of the scoutrecruit concept. Behav Ecol Sociobiol 49: 89-99.

Boch R. 1957. Rassenmässige Unterschiede bei den Tänzen der Honigbiene (Apis mellifica L.). Z Vergl Phys 40: 289-320.

Butler CG. 1954. The world of the honeybee. London, UK: Collins.

Chahal BS, Brar HS, Gatoria GS, Jhajj HS. 1986. Aggressive behaviour of A. florae towards A. mellifera in hive robbing and in foraging. J. Apic. Res., 25: 134- 138.

Dhaliwal GS, Atwal AS. 1970. Interspecific relations between Apis cerana indica and Apis mellifera. J Apic Res 9: 53-59.

Dornhaus A, Chittka L. 2004. Why do honey bees dance? Behav Ecol Sociobiol 55: 395-401.

Dornhaus A, Klügl F, Oechslein C, Puppe F, Chittka L. 2006. Benefits of recruitment in honey bees: effects of ecology and colony size in an individual-based model. Behav Ecol 17: 336-344. Duangphakdee O, Hepburn HR, Tautz J. 2011. The dance language. pp 313-330. In: Hepburn HR, Radloff SE (eds). Honeybees of Asia. Springer-Verlag, Berlin.

Dornhaus A. 2002. The role of communication in the foraging process of social bees. Department of Behavioral Physiology and Sociobiology. Würzburg, University of Würzburg.

Dyer FC, Seeley TD. 1991. Dance dialects and foraging range in three Asian honey bee species. Behav Ecol Sociobiol 28: 227234.

Dyer FC, Seeley TD. 1994. Colony migration in the tropical honey bee Apis dorsata F. (Hymenoptera: Apidae). Insectes Soc 41: 129-140.

Dyer FC. 1985a. Nocturnal orientation by the Asian honey bee, Apis dorsata. Anim Behav 33: 769-774.

Dyer FC. 1985b. Mechanisms of dance orientation in the Asian honey bee Apis florea L. J Comp Physiol A 157: 183-198.
Dyhr JP, Higgins CM. 2010. The spatial frequency tuning of optic-flowdpendent behaviors in the bumblebee, Bombus impatiens. J Exp Biol 213: 1643-1650.

Esch HE, Zhang S, Srinivasan MV, Tautz J. 2001. Honeybee dances communicate distances measured by optic flow. Nature 411: 581-583.

Esch HE. 1964. Beiträge zum Problem der Entfernungsweisung in den Schwänzeltanzen der Honigbiene. Z Vergl Phys 48: 534-546.

Gardner KE, Seeley TD, Calderone NW. 2008. Do honeybees have two discrete dances to advertise food sources? Anim Behav 75: 1291-1300.

Giurfa M. 2007. Behavioral and neural analysis of associative learning in the honeybee: a taste from the magic well. J Comp Physiol A 193: 801-824.

Gould JL. 1975. Honey bee recruitment: the dance-language controversy. Science 189: 685-693.

Gould JL. 1982. Why do honey bees have dialects? Behav Ecol Sociobiol 10: 53-56.

Greenleaf SS, Williams NM, Winfree R, Kremen C. 2007. Bee foraging ranges and their relationship to body size. Oecologia 153: 589-596.

Grüter C, Farina WM. 2009. The honeybee waggle dance: can we follow the steps? Trends Ecol Evol 24: 242-247.

Hepburn HR, Radloff SE. 2011. Honeybees of Asia. Berlin: Springer-Verlag. Hrncir M, Jarau S, Zucchi R, Barth FG. 2003. A stingless bee (Melipona seminigra) uses optic flow to estimate flight distances. J Comp Physiol A 189: 761-768.

Jander R, Jander U. 1970. On the phylogeny of gravity orientation in bees Apoidea. $\mathrm{Z}$ Vergl Phys 66: 355-368.

Johnson LK, Hubbell SP. 1974. Aggression and competition among stingless bees: field studies. Ecology 55: 120-127.

Johnson LK. 1974. The role of agonistic behavior in the foraging strategies of Trigona bees. [PhD thesis]. Berkeley, California: University of California Berkeley. 
Johnson LK. 1983. Foraging strategies and the structure of stingless bee communities in Costa Rica. Social insects in the tropics. P. Jaisson. Paris, Université Paris-Nord. 2: 31-58.

Johnson RN, Oldroyd BP, Barron AB, Crozier RH. 2002. Genetic control of the honey bee (Apis mellifera) dance language: segregating dance forms in a backcrossed colony. J Hered 93: 170-173.

Kastberger G, Schmelzer E, Kranner I. 2008. Social waves in giant honeybees repel hornets. PLoS 3: 1-16.

Kirchner WH. 1993. Vibrational signals in the tremble dance of the honeybee, Apis mellifera. Behav Ecol Sociobiol 33: 169172.

Koeniger N, Koeniger G, Gries M, Tingek S, Kelitu A. 1996. Observations on colony defense of Apis nuluensis Tingek, Koeniger and Koeniger, 1996 and predatory behavior of the hornet, Vespa multimaculata Pérez, 1910. Apidologie 27: 341-352.

Koeniger N, Koeniger G, Smith D. 2011.Phylogeny of the genus Apis. pp 2350. In: Hepburn HR, Radloff SE (eds). Honeybees of Asia. Berlin: SpringerVerlag.

Koeniger N, Vorwohl G. 1979. Competition for food among four sympatric species of Apini in Sri Lanka (Apis dorsata, Apis cerana, Apis florea, and Trigona iridipennis). J Apic Res 18: 95-109.

Koeniger N. 1982. Observations and experiments on dance communication in Apis florea in Sri Lanka. J Apic Res 21: 45-52.

Lau C, Nieh JC. 2010. Honey bee stopsignal production: temporal distribution and effect of feeder crowding. Apidologie 41: 87-95.

Lichtenberg E, Imperatriz-Fonseca VL, Nieh JC. 2010. Behavioral suites mediate group-level foraging dynamics in communities of tropical stingless bees. Insectes Soc 57: 105-113.
Lindauer M. 1956. Über die verständigung bei indischen bienen. Z Vergl Phys 38: 521557.

Michelsen A, Kirchner WH, Lindauer M. 1986. Sound and vibrational signals in the dance language of the honeybee, Apis mellifera. Behav Ecol Sociobiol 18: 207-212.

Michener CD. 1990. Classification of the Apidae (Hymenoptera). Univ Kans Sci Bull 54: 75-164.

Nagamitsu T, Inoue T. 1997. Aggressive foraging of social bees as a mechanism of floral resource partitioning in an Asian tropical rainforest. Oecologia 110: 432439.

Nagamitsu T, Inoue T. 2005. Floral resource utilization by stingless bees (Apidae, Meliponini). Pollination Ecology and the Rain Forest. New York, Spring New York. 174: 73-88.

Nieh J. C., Kruizinga K, Contrera FAL, Barreto LS, Imperatriz-Fonseca VL. 2005. Effect of group size on the aggression strategy of an extirpating stingless bee, Trigona spinipes. Insectes Soc 52: 147-154.

Nieh JC, Contrera FAL, Rangel J, ImperatrizFonseca VL. 2003. Effect of food location and quality on recruitment sounds and success in two stingless bees, Melipona mandacaia and Melipona bicolor. Behav Ecol Sociobiol 55: 87- 94.

Nieh JC, Roubik DW. 1998. Potential mechanisms for the communication of height and distance by a stingless bee, Melipona panamica. Behav Ecol Sociobiol 43: 387-399.

Nieh JC. 1993. The stop signal of honey bees: reconsidering its message. Behav Ecol Sociobiol 33: 51-56.

Nieh JC. 2010. A negative feedback signal that is triggered by peril curbs honey bee recruitment. Curr Biol 20: 310- 315.

Nieh, J. C. (2010). A negative feedback signal that is triggered by peril curbs honeybee recruitment Curr. Biol., 20 (2010), pp. 310-315

Oldroyd BP, Wongsiri S. 2006. Asian honeybees. Cambridge, Massachusetts: Harvard University Press. 
Papachristoforou A, Sueur J, Rortais A, Angelopoulos S, Thrasyvoulou A, Arnold G. 2008. High frequency sounds produced by Cyprian honeybees Apis mellifera cypria when confronting their predator, the Oriental hornet Vespa orientalis. Apidologie 39: 468- 474. Pastor KA, Seeley TD. 2005. The brief piping signal of the honey bee: begging call or stop signal? Ethology 111: 775784.

Partap U, Shukla AN, Verma LR. 2000. Comparative foraging behaviour of Apis cerana and Apis mellifera in pollinating peach and plum flowers in Kathmandu Valley Nepal. Proceedings of the 4th Asian Apicultural Association Conference, Kathmandu.

Punchihewa RWK, Koeniger N, Kevan P. G, Gadawski R. M. 1985. Observations on the dance communication and natural foraging ranges of Apis cerana, Apis dorsata, and Apis florea in Sri Lanka. J Apic Res 24: 168-175.

Radloff, S. E., H. R. Hepburn and M. S. Engel (2011). The Asian species of Apis. pp 122. In: Hepburn HR, Radloff SE (eds). Honeybees of Asia. Springer- Verlag, Berlin.

Rao SP, Raju AJS. 2002. Pollination ecology of the red sanders Pterocarpus santalinus (Fabaceae), and endemic and endangered tree species. Curr Sci 83: 1144-1148.

Rinderer TE, Beaman LD. 1995. Genic control of honey bee dance language dialect. Theor Appl Genet 91: 727-732.

Roubik DW. 1978. Competitive interactions between neotropical pollinators and Africanized honey bees. Science 201: 1030-1032.

Roubik DW. 1981. Comparative foraging behavior of Apis mellifera and Trigona corvina (Hymenoptera: Apidae) on Baltimora recta (Compositae). Rev Biol Trop 29: 177-183.

Ruttner F. 1988. Biogeography and taxonomy of honeybees. New York: SpringerVerlag.
Sakagami SF, Roubik DW, Zucchi R. 1993. Ethology of the robber stingless bee, Lestrimelitta limao (Hymenoptera: Apidae). Sociobiology 21: 237-277.

Sakagami SF. 1960. Preliminary report on the specific difference of behavior and other ecological characters between European and Japanese honeybees. Acta Hymenopterologica 1: 171-198.

Sarma MS, Esch H, Tautz J. 2004. A comparison of the dance language in Apis mellifera and Apis florea reveals striking similarities. J Comp Physiol A 190: 4953.

Sarma MS, Fuchs S, Werber C, Tautz J. 2002. Working piping triggers hissing for coordinated colony defense in the dwarf honeybee Apis florea. Zoology 105: 215223.

Sarma MS, Rodriguez-Zas SL, Gernat T, Nguyen T, Newman T, Robinson GE. 2010. Distance-responsive genes found in dancing honey bees. Genes Brain Behav 9: 825-830.

Schmelzer E, Kastberger G. 2009. 'Special agents' trigger social waves in giant honey bees (Apis dorsata). Naturwissenschaften 96: 1431-1441.

Seeley TD, Tautz J. 2001. Worker piping in honey bee swarms and its role in preparing for liftoff. J Comp Physiol A 187: 667-676.

Sihag RC, Rathi A. 1992. Foraging modes and foraging rates of different bee pollination of pigeon pea (Cajanus cajan (L.) Millsp.). Proceedings of the International Symposium on Pollination in the Tropics.

Singh S. 1959. The honeybees of India. ABC and XYZ of Bee Culture. Medina, Ohio, A. I. Root Co.: 563-565.

Somanathan H, Warrant EJ, Borges RM, Wallén R, Kelber A. 2009. Resolution and sensitivity of the eyes of the Asian honeybees Apis florea, Apis cerana, and Apis dorsata. J Exp Biol 212: 2448-2453.

Srinivasan MV, Zhang S, Altwein M, Tautz J. 2000. Honeybee navigation: Nature and calibration of the "odometer". Science 287: 8510853. 
Srinivasan MV, Zhang SW, Bidwell NJ. 1997. Visually mediated odometry in honeybees. J Exp Biol 200: 2513-2522.

Su S, Cai F, Si A, Zhang S, Tautz J, Chen S. 2008. East learns from West: Asiatic honeybees can understand dance language of European honeybees. PLoS 3: 1-9.

Tan K, Yang MX, Radloff SE, Hepburn HR, Zhang ZY, Luo LJ, Li H. 2009. Dancing to different tunes: heterospecific deciphering of the honeybee waggle dance. Naturwissenschaften 95: 11651168.

Tanner DA, Visscher PK. 2010. Adaption or constraint? Reference-dependent scatter in honey bee dances. Behav Ecol Sociobiol 64: 1081-1086.

Tautz J. 2008. The buzz about bees: biology of a superorganism. Berlin: Springer-Verlag.

Thom C, Gilley DC, Tautz J. 2003. Worker piping in honey bees (Apis mellifera): the behavior of piping nectar foragers. Behav Ecol Sociobiol 53: 199-205.

Tigari S. 1971. On the biology and manipulation of Apis (Micrapis) florae F. in Iran. Proceedings of the 23th International Beekeepers Congress.
Towne WF, Gould J. L. 1988. The spatial precision of the honey bee's dance communication. J Insect Behav 1: 129156.

Vitthalrao B. Khyade, Vishakha R. Kakade, Aishwarya R. Inamake 2015. Communication and Pollination in Apis indica (L.), The Significant Phenomenon. Annals of Plant Sciences. 4 (03), 10331050

Von Frisch K. 1946. Die Tänze der Bienen. Öst Zool Zeit 1: 1-48.

Von Frisch K. 1967. The dance language and orientation of bees. Cambridge, Massachusetts: Belknap Press.

Weidenmuller A, Seeley TD. 1999. Imprecision in waggle dances of the honeybee (Apis mellifera) for nearby food sources: error or adaptation? Behav Ecol Sociobiol 46: 190-199.

Yang MX, Tan K, Radloff SE, Hepburn HR. 2011. Interspecific interactions among Asian honeybees. pp 445-462. In: Hepburn HR, Radloff SE (eds). Honeybees of Asia. Springer-Verlag, Berlin.

\section{How to cite this article:}

Pratiksha Sanjay Bandgar, Kajal Appasaheb Pondkule and Vitthalrao B. Khyade. 2018. Fascinating Communication in Honey Bees. Int.J.Curr.Microbiol.App.Sci. 7(09): 3704-3718. doi: https://doi.org/10.20546/ijcmas.2018.709.460 